\title{
Dermatoglyphs in congenital heart disease
}

\author{
T J DAVID \\ From the Department of Child Health, University of Manchester, Manchester
}

SUMMARY The palmar dermatoglyphs of 800 patients with anatomically proven congenital heart $\frac{\vec{\omega}}{\omega}$ disease were compared with prints from 1000 controls. A review of the previous studies revealed major technical deficiencies, and the present study failed to confirm most of the previously reported positive findings.

An overall increase in the incidence of hypothenar patterns was found, probably explaining the $\dot{i}$ previous suggestion of increased atd angle in congenital heart disease. A large number of statistical $\stackrel{\oplus}{\perp}$ comparisons inevitably produced a few 'significant' results, most of which were inconsistent in o various ways.

Two percent of cases were found to have a rare epidermal ridge malformation, ridge dissociation. The nature of the relationship between this and congenital heart disease is obscure.

Claims that there are diagnostically useful dermatoglyphic changes in congenital heart disease $\stackrel{\mathbb{\Phi}}{\square}$ can be disregarded.

Although dermatoglyphs have attracted much interest in recent years, the quality of much of the work is abysmal. Publications on dermatoglyphs in congenital heart disease are no exception, and all previous studies ${ }^{1-34}$ suffer from at least one of the major deficiencies listed below. These faults are to be found in many other dermatoglyphic studies.

(1) An accurate cardiac diagnosis was often not made, and cases were often not subdivided into different anatomical groups. ${ }^{1516}$ There are important embryological and genetic differences between different cardiac lesions and it is pointless to lump them all together.

(2) Even when a group of apparently similar cases are studied, there will be considerable aetiological heterogeneity. For example, a group of persistent ductus arteriosus (PDA) may include a few cases resulting from rubella, which itself may effect the dermatoglyphs. ${ }^{35}$

(3) Very small numbers were often used..$^{51415}$ With the enormous natural dermatoglyphic variation occurring in normal people, small numbers lead to serious sampling errors.

(4) Inadequate or inappropriate statistical tests were often used, for example when examing the TRC. ${ }^{35}$

(5) Some studies only examined fingerprints, ${ }^{2} 714$ and others only palm prints. ${ }^{145}$ Two studies examined only the right palm. ${ }^{89}$

Received for publication 22 October 1980
(6) The maximal atd angle ${ }^{36}$ was used by most investigators. When it is stated that the atd angle was 'increased', one is left in doubt as to $\bar{\partial}$ whether (a) the real $t$ triradius was distally displaced, or (b) there was an excess of hypothenar $\stackrel{\circ}{\circ}$ patterns, or (c) a combination of (a) and (b) $\overrightarrow{\overrightarrow{0}}$ applied. This confusion would be avoided by 3 studying separately the presence or absence of hypothenar patterns, and measuring the atd angle from the real $t$ triradius. It is often forgotten that Penrose ${ }^{36}$ specifically introduced the maximal atd angle as a means of discriminating between normal subjects and those with Down syndrome. To apply it generally is to conceal important information.

(7) The atd angle was not corrected for lateral 옹 deviation, ${ }^{37}$ nor was age taken into account $D$ when comparing patients with controls. ${ }^{38}$ 을. Furthermore, the prints used for measuring the atd angle were not taken in a standard way, introducing errors because of abduction of the ${ }_{N}$ fingers. ${ }^{37}$

(8) Although sex is well known to affect the TRC, this was sometimes ignored and the TRCQ examined in patients of both sexes combined. ${ }^{29}$

It has been claimed that an increased number of $\stackrel{\oplus}{\stackrel{\oplus}{+}}$ a particular fingerprint pattern in any particular $\frac{T^{\circ}}{\circ}$ group of cases is the result of a small number of $\frac{\vec{D}}{\mathbb{D}}$ cases in each group, and that these few cases con- $\frac{\Omega}{\square}$ stituted a genetically determined fraction. whose $\stackrel{\mathbb{D}}{\triangle}$ 
dermatoglyphs differ from other patients'. ${ }^{2}$ It was later suggested that dermatoglyphs, by detecting this genetic fraction of cases, might be useful for genetic counselling. ${ }^{3}$ Another study suggested an inverse relationship between the TRC and the systolic pulmonary artery pressure. ${ }^{7}$ Most studies, however, merely claimed an increased number of certain dermatoglyphic traits in patients with congenital heart disease, sometimes suggesting that this might be diagnostically useful. Despite these claims of diagnostic use, no single study has ever pursued the subject to its logical conclusion by seeing whether possession of the dermatoglyphic characters that are apparently distinctive of a particular cardiac lesion in fact allows diagnosis to be made. In fact this approach has only ever been taken once, ${ }^{39}$ and for the other diseases studied, diabetes, schizophrenia, duodenal ulcer, asthma, and various cancers, it was a failure.

One report even claimed that by analysing a baby's palm prints it is possible "to detect serious heart defects in time for life-saving surgery". ${ }^{40}$ This, and other less dramatic claims, will be examined in the present study, which will also attempt to overcome the problems and deficiencies of previous reports.

\section{Patients and methods}

Everyone studied lived in the south and west of England. The controls, 500 males and 500 females, consisted of healthy unrelated subjects representing as far as possible a cross section of social classes.

A total of 800 patients with cardiovascular malformations was studied. Only those who had undergone cardiac catheterisation or cardiac surgery were studied, thus excluding patients with undiagnosed heart lesions. The aim was to study as many accurately diagnosed patients as possible, and no attempt was made to select patients with a particular defect. Patients with chromosome abnormalities or inherited or non-inherited recognisable syndromes, or those in whom there was a known cause for the defect (for example, rubella), were not studied. The mere presence of a non-cardiac malformation did not exclude a case from the study.

Only patients over 6 months of age were studied because of the difficulties of obtaining good prints in babies. The prints were recorded on specially prepared fingerprint forms using black fingerprint ink. Rolled and plain impressions were obtained from all fingers, and two sets of palm prints were recorded, one of which was taken with the fingers fully adducted (for atd angle measurement).

The dermatoglyphic features studied were the same as in a previous study of tuberous sclerosis, ${ }^{38}$ which used the same controls.

The 425 female and 375 male patients were divided into separate diagnostic groups. Groups of very small numbers of cases were excluded. Where more than one cardiovascular lesion was present (for example, aortic stenosis and atrial septal defect) the case was included in both diagnostic groups.

In each diagnostic group the following were compared between patients and controls.

(1) Fingerprint patterns on individual digits: sexes separate.

(2) Total ridge count: sexes separate.

(3) Thenar patterns: sexes separate.

(4) Hypothenar patterns: sexes separate.

(5) Interdigital patterns: sexes separate.

(6) Palmar creases: sexes separate.

(7) Mean ridge breadth (MRB): matched age groups, sexes separate.

(8) Summed (right and left) corrected atd angle: matched age groups, sexes combined. ${ }^{38}$

The $a-b$ ridge count was used to calculate the mean ridge breadth but was not used for comparisons between patients and controls.

For analysis and comparison of fingerprint patterns, no group of fewer than ten subjects was examined. For analysis of palm patterns and for quantitative analyses, no group of fewer than 20 subjects was examined.

\section{Results}

The results for the 1000 healthy controls have been previously published. ${ }^{38}$ The positive results for patients are summarised as follows.

GROUP A. ENDOCARDIAL CUSHION DEFECTS

(12 MALES, 12 FEMALES)

(1) Significant (by Fisher's test, $p=0.02$ ) deficit of ulnar loops on right index finger of females. Same trend on females' left index finger, but not in males.

(2) Significant (by Fisher's test, $p=0.03$ ) excess of whorls on right middle finger of females. Reverse trend on left middle finger of females and right middle finger of males.

GROUP B. SECUNDUM ATRIAL SEPTAL DEFECT (37 MALES, 64 FEMALES)

(1) Significant $\left(\chi_{1}^{2}=5.9, p<0.05\right)$ excess of arches on right index finger of males. Same trend on left index finger of males and right index finger of females.

(2) Significant $\left(\chi_{1}^{2}=4.9, p<0.05\right)$ excess of left hypothenar patterns in males, mainly distal and 
outer loops. Similar trend in right palm of males, but not females.

(3) Significant (by Fisher's test, $p=0.025$ ) excess of patients with distally displaced $t$ triradii ( $R$ plus $\mathrm{L}$ corrected atd angle over 110 degrees) in the age group 8 years and over. Same trend in the age group 4 to 7 years.

GROUP C. VENTRICULAR SEPTAL DEFECT

( 83 MALES, 82 FEMALES)

This, the largest group of patients, showed no significant differences from the controls.

\section{GROUP D. PERSISTENT DUCTUS ARTERIOSUS}

(20 MALES, 64 FEMALES)

(1) Significant $\left(\chi_{1}^{2}=6.9, p<0.01\right)$ excess of whorls on left index finger of females. Same trend present on right index finger of females. Males showed the reverse trend.

(2) Significant $\left(\chi_{1}^{2}=4.0, p<0.05\right)$ deficit of whorls on left ring finger of males. No similar trend on right ring finger of males or females.

(3) Significantly (Wilcoxon-White test quotient $2 \cdot 20$, $\mathrm{p}<0.05$ ) higher TRC in females, males showing the reverse trend.

GROUP E. FALLOT'S TETRALOGY

(60 MALES, 64 FEMALES)

(1) Significant $\left(\chi_{1}^{2}=5 \cdot 6, p<0 \cdot 05\right)$ deficit of thenar patterns in males. Similar trends in females.

(2) Significantly (Wilcoxon-White test quotient $3 \cdot 67, \mathrm{p}<0.001$ ) lower TRC in males. Females showed an almost significant (test quotient $1 \cdot 89, \mathrm{p}=0.059$ ) reverse trend (that is, higher TRC).

(3) Significant $\left(\chi_{1}^{2}=4.5, p<0.05\right)$ excess of right hypothenar outer loops in males. Similar trend in females, but not on the left in either sex.

(4) Significant deficit of right $\left(\chi_{1}^{2}=14 \cdot 4, p<0 \cdot 001\right)$ and left $\left(\chi_{1}^{2}=4 \cdot 7, \mathrm{p}<0.05\right)$ hypothenar patterns in females.

GROUP F. PULMONARY STENOSIS

( 51 MALES, 49 FEMALES)

There were no significant differences between patients and controls.

GROUP G. AORTIC VALVE STENOSIS

(40 MALES, 13 FEMALES)

(1) Significant $\left(\chi_{1}^{2}=7 \cdot 8, \mathrm{p}<0.01\right)$ increase in right hypothenar patterns in males, the same trend being present on the left. Females did not show this trend.
GROUP H. TRANSPOSITION OF GREAT VESSELS (29 MALES, 14 FEMALES)

(1) Significant $\left(\chi_{1}^{2}=4.0, p<0.05\right)$ deficit of patterns on the right third interdigital area in females, the same trend being present on the left. This trend was not shown in males.

(2) Significant (Fisher's test, $p=0.001$ ) excess of ڤి left hypothenar outer loops in females.

(3) Significant excess of unusual hypothenar patterns (arch, composite, double proximal axial triradius $^{34}$ ) on (a) left palm of females (Fisher's test, $p=0.023$ ), (b) right palm of females

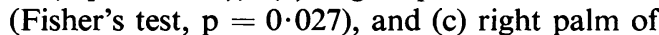
males (Fisher's test, $\mathrm{p}=0 \cdot 004$ ).

\section{GROUP I. COARCTATION OF AORTA}

(36 MALES, 21 FEMALES)

(1) Significant (Fisher's test, $p=0.008$ ) excess of radial loops on the right index finger of female $\overrightarrow{0}$ patients, the same trend being present on the left index finger of females but not in males on $\stackrel{0}{\square}$ either index finger.

(2) Significant excess of hypothenar twinned loops $\overrightarrow{0}$ on both palms of males (Fisher's test; right $\stackrel{\infty}{-}$ $\mathrm{p}=0.03$, left $\mathrm{p}=0.003$ ).

(3) Significant excess of hypothenar outer loops on both palms of females (Fisher's test; right $\mathrm{p}=0.005$, left $\mathrm{p}=0.002$ ).

\section{PALMAR CREASES}

The results for all 800 patients not subdivided up $\overrightarrow{\vec{O}}$ are shown in table 1. As expected, a greater pro- 3 portion of patients had a single transverse crease than the controls. An unexpected sex difference was? found, the proportion of male patients having a single transverse crease being significantly higher $\left(\chi_{1}^{2}=4 \cdot 0, \mathrm{p}<0.05\right)$.

\section{HYPOTHENAR PATTERNS}

The results for individual diagnostic groups are given

TABLE 1 Palmar creases in 800 subjects with congenital heart disease and 1000 controls

\begin{tabular}{|c|c|c|c|c|c|}
\hline & $\begin{array}{l}\text { Normal } \\
\text { creases }\end{array}$ & $\begin{array}{l}\text { Left } \\
\text { single } \\
\text { crease } \\
\text { only }\end{array}$ & $\begin{array}{l}\text { Right } \\
\text { single } \\
\text { crease } \\
\text { only }\end{array}$ & $\begin{array}{l}\text { Bilateral } \\
\text { single } \\
\text { creases }\end{array}$ & $\begin{array}{l}\text { Total } \\
\text { with } \\
\text { single } \\
\text { crease }\end{array}$ \\
\hline \multicolumn{6}{|l|}{ Males } \\
\hline Controls & $\begin{array}{l}497 \\
(99.4 \%)\end{array}$ & $\begin{array}{l}3 \\
(0 \cdot 6 \%)\end{array}$ & - & - & \multirow{2}{*}{$\begin{array}{l}3 \\
(0.6 \%) \\
16 \\
(4.3 \%)\end{array}$} \\
\hline Patients & $\begin{array}{l}359 \\
(95.7 \%)\end{array}$ & $\begin{array}{l}9 \\
(2.4 \%)\end{array}$ & $\begin{array}{l}2 \\
(0.5 \%)\end{array}$ & $\begin{array}{l}5 \\
(1 \cdot 3 \%)\end{array}$ & \\
\hline \multicolumn{6}{|l|}{ Females } \\
\hline Controls & $\begin{array}{l}498 \\
(99.6 \%)\end{array}$ & $\begin{array}{l}2 \\
(0.4 \%)\end{array}$ & - & - & \multirow{2}{*}{$\begin{array}{l}2 \\
(0.4 \%) \\
7 \\
(1.6 \%)\end{array}$} \\
\hline Patients & $\begin{array}{l}418 \\
(98.4 \%)\end{array}$ & $\begin{array}{l}3 \\
(0.7 \%)\end{array}$ & $\begin{array}{l}1 \\
(0 \cdot 2 \%)\end{array}$ & $\begin{array}{l}3 \\
(0.7 \%)\end{array}$ & \\
\hline
\end{tabular}


TABLE 2 Hypothenar patterns in 800 subjects with congenital heart disease and 1000 controls

\begin{tabular}{lll}
\hline & Pattern & No pattern \\
\hline $\begin{array}{ll}\text { Males } \\
\quad \text { Controls }\end{array}$ & $320(32 \cdot 0 \%)$ & \\
Patients & $297(39 \cdot 6 \%)$ & $680(68 \cdot 0 \%)$ \\
& $\chi_{1}^{2}=10 \cdot 5, \mathrm{p}<0.01$ & $453(60 \cdot 4 \%)$ \\
& & \\
Females & $368(36.8 \%)$ & $632(63.2 \%)$ \\
$\quad$ Controls & $375(44 \cdot 1 \%)$ & $475(55.9 \%)$ \\
Patients & $\chi_{1}^{2}=9 \cdot 9, \mathrm{p}<0.01$ & \\
&
\end{tabular}

above. However, when all 800 patients were combined, they were found to have a significant excess of hypothenar patterns (table 2). This excess was spread fairly evenly among all hypothenar patterns, with the largest excess being of outer loops, proximal loops, and double proximal axial triradii.

\section{RIDGE DISSOCIATION}

None of the 1000 controls showed ridge dissociation, but this was present in $19(2.4 \%)$ of the 800 patients. Eight of these had Fallot's tetralogy, but otherwise no particular cardiac lesion appeared in this group. Where ridge dissociation was present on the palm this was usually in the region of the $t$ triradius, but also sometimes in the hypothenar and interdigital areas.

\section{Discussion}

\section{CONTROLS}

It is difficult to know what would comprise a perfect control group. Ideally such subjects would differ from patients only by the absence of cardiac malformation. To obtain subjects with the same genotype and with the same experience of intrauterine events as the patients is clearly impossible. Like-sexed unaffected sibs might be useful ${ }^{41}$ in some situations, but are still far from ideal.

Both patients and controls were living in the south and west of England, a large area. This may seem satisfactory, but findings such as those of Roberts and Coope ${ }^{42}$ in the South Midlands suggest quite important local geographical dermatoglyphic variation. Clearly a study such as the present one could not be done in a small village, and one is left with the choice of a regional or national study, the aim being to cancel out the effect of local variation by drawing from a large area.

PATIENT SELECTION

Although previous investigators have not commented on this, it is important to recognise that patients in a series such as this are a selected group, and this is essential if one is to extrapolate the findings to the general population.

By not studying cases under 6 months, certain severe disorders such as the hypoplastic left heart syndrome will escape study. Severe fatal cases of other lesions will also be missed. However, by insisting on only cases where an accurate diagnosis had been made, many mild cases not warranting cardiac catheterisation will also be missed.

In short, it is thought that the groups of secundum ASD, VSD, pulmonary stenosis, and aortic stenosis tend to be the more severe cases. The group of endocardial cushion defects tends to contain the milder cases, and, in terms of severity of the lesion, the groups of PDA, Fallot's tetralogy, coarctation, and transposition are thought to be fairly representative.

\section{FINGERPRINT PATTERNS}

Of a very large number of statistical comparisons, there were only six significant results. In several the trends were not consistent in both hands or both sexes, and it is unlikely that these findings would occur in another series. It appears that fingerprint patterns are not affected in any of the major groups of cardiac defects studied here.

\section{TOTAL FINGER RIDGE COUNT}

The only two significant results were accompanied by opposite trends in the other sex studied, and again it rather appears that the TRC is not altered in congenital heart disease.

\section{MEAN RIDGE BREADTH}

Comparisons were only possible in three groups because of the need to subdivide by age and sex. Females over the age of 20 with ASD, males aged 4 to 7 years with VSD, and males aged 4 to 7 with Fallot's tetralogy constituted the three groups. In none was there any significant departure from the figures for controls.

\section{SUMMED CORRECTED at $d$ ANGLE}

Subjects with congenital heart disease were notable for having a normally placed $t$ triradius. The only possible departure from this was the group of 78 subjects over the age of 8 years with ASD: eight of these $(10 \%)$ had a summed corrected atd angle over $110^{\circ}$. The same trend, not reaching significance, was found in the 17 subjects aged 4 to 7 years: two of them $(12 \%)$ had a summed corrected atd angle over $120^{\circ}$ (the arbitrary cut-off point for this age group). The control figures are $4 \cdot 2 \%$ (those over 8 years of age) and $3 \%$ (those aged 4 to 7 years). Similar 
trends, though not statistically significant, have been noted previously, ${ }^{10} 11$ though the methodology was unsatisfactory. In general, it appears that significant changes in the atd angle are not found in congenital heart disease. Previous reports suggesting the reverse are probably partly attributable to the use of the maximal atd angle and the failure to recognise the presence of hypothenar patterns.

\section{HYPOTHENAR PATTERNS}

It is here that the results are most interesting, for there does appear to be a significant increase in the proportion of subjects with hypothenar patterns of all sorts. Some trends are so strong that significant results are found even when single patterns are studied within individual groups of subjects.

A previous report suggested a specific association between a double proximal axial triradius (DPAT) ${ }^{43}$ and septal defects. The present study has shown a significant overall increase in DPAT, significant in both sexes, but not confined to septal defects. However, another study ${ }^{44}$ has failed to confirm this, finding that if anything a DPAT is associated with pulmonary stenosis.

PALMAR CREASES

Several authors ${ }^{611} 1223$ report no significant increase in the frequency of a single transverse palmar crease in congenital heart disease. Nevertheless it is clinical experience (and the finding of others ${ }^{45}$ ) that a single crease is a non-specific sign that is sometimes found in patients with malformations, and one might therefore have expected to find a small increase in the incidence of a single crease in this study.

As the incidence of a single crease was unusually low in the controls it is difficult to come to any firm conclusion in this study. If there is a true increased incidence of single crease in congenital heart disease then it is small and of no clinical significance.

\section{RIDGE DISSOCIATION}

Ridge dissociation is an extremely rare congenital malformation of epidermal ridges, sometimes inherited as an autosomal dominant trait. ${ }^{46} \mathrm{~A}$ previous report ${ }^{46}$ found only two cases among 430 patients with congenital heart disease, but this was an underestimate and failed to detect some examples of ridge dissociation. It is not clear at present why a malformation of epidermal ridges should be associated with cardiovascular malformations.

\section{Conclusions}

Claims that congenital heart disease is associated with characteristic dermatoglyphic patterns are probably false. The few associations that reached statistical significance in this large study were generally internally inconsistent and must be viewed with caution in view of the very large number of statistical comparisons that were made. An overall increase in hypothenar patterns is probably genuine, and may explain previous reports of supposedly displaced $t$ triradii in congenital heart disease.

It appears that a rare congenital malformation of epidermal ridges, dissociation, is found in about $2 \%$ of cases of congenital heart disease. The specific association with Fallot's tetralogy may be a little stronger than this.

Suggestions that dermatoglyphs are diagnostically useful in congenital heart disease can be completely dismissed.

This work forms part of a PhD thesis submitted to the University of Bristol. The research was financed by grants from the Medical Research Council, the United Bristol Hospitals, and the South Western Regional Health Authority. I am indebted to Miss E H L Duncan and Mrs A F Morris for their statistical help, to Dr D W Barritt, Dr J Jancar, Professor J H Peacock, the late Professor A G Riddell, and Professor N R Butler for their help and encouragement, and to $\mathrm{Mr} \mathrm{A}$ Griffiths and police officers in Bristol and London for their training, help, and advice. Mrs C Webb very kindly typed the manuscript.

\section{References}

1 Hale AR, Phillips JH, Burch EG. Features of palmar dermatoglyphics in congenital heart disease. JAMA 1961; 176:41-5.

2 Cascos AS. Finger-print patterns in congenital heart disease. Br Heart $J 1964 ; 26$ :524-7.

3 Cascos AS. Dermatoglyphs in congenital heart disease. A familial survey of 100 cases. Acta Paediatr Scand 1968;57:9-11.

4 Cascos AS. Palm-print pattern in congenital heart disease. Br Heart J 1965;27:599-603.

5 Takashina T, Yorifuji S. Palmar dermatoglyphics in heart disease. JAMA 1966;197:689-92.

6 Emerit I, Vernant P, Corone P. Les dermatoglyphes des malades porteurs d'une cardiopathic congenitale. Acta Genet Med Gemellol (Roma) 1968;17:523-39.

7 Cascos AS, Hermida LF. Dermatoglyphs in Eisen- $N$ merger's reaction. Acta Cardiol 1969;24:382-7.

8 Cascos AS. Genetics of Fallot's tetralogy. Br Heart $J \mathrm{~W}$ 1971;33:899-904.

9 Cascos AS. Genetics of pulmonic stenosis. Acta Cardiol 1972;27:316-30.

10 Cascos AS. Genetics of atrial septal defect. Arch Dis Child $\stackrel{\mathscr{D}}{\mathscr{D}}$ $1972 ; 47: 581-8$.

11 Alter M, Schulenberg R. Dermatoglyphics in congenital heart disease. Circulation 1970;41:49-54.

12 Preus M, Fraser FC, Levy EP. Dermatoglyphics in $\overparen{D}$ congenital heart malformations. Hum Hered 1970;20: $388-402$.

.


13 Birnholz JC. Dermatoglyphics in congenital heart disease. AJR 1972;116:539-47.

14 David TJ. Fingerprints in congenital heart disease. Bristol Med Chir J 1969;84:167-9.

15 Saksena PN, Kumar N. Evaluation of dermatoglyphics in congenital heart disease and Turner's syndrome. Indian Pediatr 1968;5:315-25.

16 Krooth RS. The aetiology of human malformations with special reference to congenital heart disease and achondroplasia. PhD thesis, University of London, 1952.

17 Weninger M, Kainol F, Rotherbuchner G. Schober Hautleistenuntersuchungen Bei Angeborenen Missbilddungen des Herzens und der Grossen Gefasse. Wien Klin Wochenschr 1966;78:905-6.

18 Saller K, Glowatzki G. Kongenitale Herzfehler und Hautleisten System. Med Klin 1967;62:1458-60.

19 Reyes L. Abnormal dermatoglyphics in congenital heart disease. Proc Inst Med Chic 1968;27:86-7.

20 Ceccarelli M, Giorgi PL, Paci A, Raggio R, Vizzoni L. Dermatoglifi palmari e cardiopatie congenite. Minerva Pediatr 1968;20:940-2.

21 Cascos AS, Sanchez-Harguindey L, Rabago PD. Cardioauditory syndromes. Cardiac and genetic study of 511 deaf-mute children. Br Heart J 1969;31:26-33.

22 Ceccarelli M, Giorgi PL, Paci A. Ulteriore contributo allo studio dei dermatoglifi nelle cardiopatie congenite: “a - b ridge count". Minerva Pediatr 1969;21:867-9.

23 Burget W, Collard P, Jovanovic $M$. Etude des malformations extracardiaques et des anomalies du dermatoglyphe d'un groupe de cardiopathes congenitaux. Acta Cardiol 1970;25:291-302.

24 Klimentova T, Hanulikova M, Karasova M, Pagacova E. Changes in dermatoglyphs in certain congenital cardiac defects. Bratisl Lek Listy 1972;57:172-9.

25 Takashina T, Nakamura K. Palmar dermatoglyphics in heart disease. Singapore Med J 1973;14:287-9.

26 Wlodarz A. Dermatoglyphics in congenital heart defects. Roczniki Pomorskiej Akademii Medycznej im Generala Karola K Swierczewskiego 1973;19:484-99.

27 Reed T, Shields L, Nance WE. Dermatoglyphic heterogeneity in mongols with congenital heart disease. $A m ~ J$ Hum Genet 1973;25:109-10.

28 Hook EB, Aldrich M, Bonenfant R, et al. The distalmost palmar axial triradius in children with selected types of isolated congenital heart disease. Teratology 1974;9: 233-8.

29 Goto M, Onouchi Z, Tohisawa M, Nakata K, Goto M, Kusunoki T. Quantitative analysis of dermatoglyphics. 1. Total ridge count. Jpn Circ J 1977; 41 :1353-6.
30 Cascos AS, Sagredo JMG. Genetics of patent ductus arteriosus. Basic Res Cardiol 1975;70:456-66.

31 Vormittag W, Ferlitsch A. Dermatoglyphic investigations in a kindred manifesting familial atrial septal defect (ostium secundum). A contribution to the problem of genetic counselling in multifactorial inheritance. Wien Klin Wochenschr 1975;87:99-101.

32 Kacejova M, Srsen S. Dermatoglyphic analysis in patients with inborn heart defects-qualitative and quantitative values of fingers. Bratisl Lek Listy 1977;68: 684-92.

${ }^{33}$ Kacejova M, Srsen S. Dermatoglyphic analysis in patients with congenital heart defects-some palm parameters. Bratisl Lek Listy 1978;69:156-62.

34 Goto M, Onouchi Z, Tomisawa M, Nakata K, Goto $M$, Kusunoki T. Quantitative analysis of dermatoglyphics. 3. Patients with congenital heart disease, and their parents. Jpn Circ J 1979;43:9-13.

35 Schaumann B, Alter M. Dermatoglyphics in medical disorders. New York: Springer Verlag, 1976.

36 Penrose LS. The distal triradius $t$ on the hands of parents and sibs of mongol imbeciles. Ann Hum Genet 1954;19: 10-38.

37 David TJ. The palmar axial triradius t. A new method of location. Hum Hered 1971 ; 21 :624-7.

38 David TJ. Palmar dermatoglyphs in tuberous sclerosis. J Med Genet 1972;9:443-7.

39 Fuller IC. Dermatoglyphics: a diagnostic aid? J Med Genet $1973 ; 10$ :165-9.

40 Anon. Hearts and palms. Newsweek 1970 Sept 14: 58.

41 Roberts DF, Humphreys C, Chavez JB. Dermatoglyphics and disease. Anthropologia 1976;23:233-8.

42 Roberts DF, Coope E. Dermatoglyphic variation in the South Midlands. Heredity $1972 ; 29: 293-305$.

43 David TJ. Unusual finding during dermatoglyphic study. $J$ Pediatr $1971 ; 79: 343$.

44 Hook EB, Bonenfant R. Parathenar palmar pattern: a dermatoglyphic sign of possible clinical significance. Hum Hered 1975;25:509-12.

45 Davies PA, Smallpiece V. The single transverse palmar crease in infants and children. Dev Med Child Neurol $1963 ; 5: 491-6$.

46 David TJ. Congenital malformations of human dermatoglyphs. Arch Dis Child 1973;48:191-8.

Requests for reprints to Dr T J David, Booth Hall Children's Hospital, Charlestown Road, Blackley, Manchester M9 2AA. 